\title{
What Was the Name of That Drug? How Medical Students can Make the Most Out of Their Education
}

\author{
Aryan Riahi,' David Jung.'
}

\section{The Experience}

Information overload

As lifelong scholars, we are committed to refining our medical acumen. This is not an easy task, as medical students may be intimidated by the sheer wealth of information and the constant updates. In the beginning of our medical journey, we were also overwhelmed as learning felt like attempting to drink from fire hydrants.

Nevertheless, medical school offered learning strategies we had not experienced before, and we were encouraged to take advantage of them to maximize our learning. In hopes of sharing some of our experiences, here is a snapshot of what we found to be effective.

Case-based learning: taking an active approach to learning In medical school, we continued to have traditional lectures similarly to our studies prior to medicine. However, they were now accompanied by a novelty called case-based learning (CBL) sessions. During CBL, a small group of students is presented with a weekly hypothesized patient case. The case aligns with lecture materials, allowing students to apply their knowledge in theoretical clinical environments. Discussions include formulating differential diagnoses, ordering investigations, and management plans once a working diagnosis was established. Facilitators are also present and guide students through self-directed clinical decision instead of serving the traditional instructional roles.

Compared to the more passive-styled learning in lectures, CBL takes an active approach requiring students to think critically. These teambased sessions began in the 1960 s at McMaster University in Canada. By deliberately providing students with vague patient presentations, CBL is designed to make students struggle and ponder. Oftentimes, patients would initially have nonspecific clinical presentations such as fatigue. We were forced to keep our differential diagnosis very broad and systemically rule out conditions as more information became available. This was repeated multiple times in CBL, each with a different patient. Looking back, the repetition allowed us to ingrain a systematic method in approaching patient presentations. These teambased sessions also exposed us to the collaborative working environments of healthcare institutions.

Furthermore, group learning also allows learners to identify inconsistencies in their knowledge. ${ }^{2}$ There were times in which materials we thought we had mastered were in fact, unmastered. For instance, we would realize our gaps in the pathophysiology of diabetic ketoacidosis while attempting to explain to classmates. These gaps had been previously overlooked and prompted us to reinforce our knowledge.

It is a well-known fact that active learning produces better outcomes. Likewise, team-based learning experiences like CBL are associated with improved short- and long-term outcomes, as measured by examination results. 3 For some, CBL may require more preparation, and "risk-taking" moments, in which we present our best evidencebased opinions to our peers for discussion. Still, these are paid off by better retaining and higher learning outcomes. With CBL and simila team-based approaches already present in many schools, these sessions should be trumpeted more and not overlooked by students as opportunities to consolidate lecture materials.

\section{Retaining information}

Analogous to the benefits of active learning, active recalling is superior to its passive counterpart. Active methods of recalling information help consolidate the information much more effectively than passively restudying facts. For example, the ability to consciously recall the adverse effects of statins without the use of cues will help consolidate the list far better than passively re-reading them. Active recall would allow students to better manage the large volume of information and also retain it for long-term use in their career.

One popular form of active recall is the testing effect. While many students view tests solely as assessments, they are also an excellent way of retaining knowledge. Similarly, to having a discussion, testing ourselves allows for the identification of gaps in our knowledge. oftentimes, it is too easy to convince ourselves that we have retained the information after passively reading the material. It may also seem intimidating to test our knowledge, in fear of recognizing our own gaps and having to return to the material. However, these gaps can only be recognized when we search for them by testing ourselves. Leaving them unattended could not only lead to lowered academic performance in the short-term but also compromised patient care in the long-term. A randomized controlled trial examined the effects of testing on the learning of residents.4 All residents took final examinations, but certain individuals were randomized to intermittent testing while others passively reviewed the study material. At the end, groups that exposed themselves to intermittent tests had better learning outcomes. The dual role of testing can be explored by medical students for better retention and studying efficiency.

\section{Learn for the patients}

As lifelong learners, it is crucial to recognize that the objective of learning information lies beyond the successful completion of an upcoming exam. Learn for the long term. Learn for the patients. 


\section{Experience}

\section{References}

1. Hendry GD, Frommer $M$, Walker RA. Constructivism and problem-based learning. Journal of Further and Higher Education. 1999;23(3):369-371.

2. Hrynchak $P$, Batty $H$. The educational theory basis of teambased learning. Med Teach. 2012;34(10):796-801.
3. Warrier KS, Schiller JH, Frei NR, Haftel HM, Christner JG. Longterm gain after team-based learning experience in a pediatric clerkship. Teach Learn Med. 2013;25(4):300-305.

4. Larsen DP, Butler AC, Roediger HL. Repeated testing improves long-term retention relative to repeated study: A randomised controlled trial. Med Educ. 2009 Dec;43(12):1174-1181.

\section{Acknowledgments}

None.

Conflict of Interest Statement at Funding

The Authors have no funding, financial relationships or conflicts of interest to disclose.

Author Contributions

Conceptualization: DJ. Writing - Original Draft: DJ, and AR. Writing - Review atEditing: DJ, and AR. Supervision: AR.

Cite as:

Riahi A, Jung D. What Was the Name of That Drug? How Medical Students can Make the Most Out of Their Education. Int J Med Students. 2019 MayAug; $7(2): 50-51$. 